\title{
Rahnella perminowiae sp. nov., Rahnella bonaserana sp. nov., Rahnella rivi sp. nov. and Rahnella ecdela sp. nov., isolated from diverse environmental sources, and emended description of the genus Rahnella
}

by Brady, C., Asselin, J.A., Beer, S., Brurberg, M.B., Crampton, B., Venter, S., Arnold, D. and Denman, S. 


\section{sp. nov., Rahnella rivi sp. nov. and Rahnella ecdela sp. nov. from}

\section{diverse environmental sources and the emended description of the} genus Rahnella.

\subsection{Author names}

Carrie Brady ${ }^{1 *}$, Jo Ann Asselin², Steven Beer ${ }^{3}$, May Bente Brurberg ${ }^{4,5}$, Bridget Crampton ${ }^{6}$, Stephanus Venter ${ }^{7}$, Dawn Arnold ${ }^{1,8}$, Sandra Denman ${ }^{6}$

\subsection{Affiliation}

${ }^{1}$ Centre for Research in Bioscience, Faculty of Health and Life Sciences, University of the West of England, Bristol, United Kingdom

${ }^{2}$ Emerging Pests and Pathogens Research Unit, Robert W. Holley Centre for Agriculture and Health, Agricultural Research Service, United States Department of Agriculture, Ithaca, New York, USA

${ }^{3}$ Section of Plant Pathology and Plant-Microbe Biology, School of Integrative Plant Sciences, Cornell University, Ithaca, NY, USA

${ }^{4}$ Division of Biotechnology and Plant Health, NIBIO, Norwegian Institute of Bioeconomy Research, Ås, Norway

${ }^{5}$ Department of Plant Sciences, Norwegian University of Life Sciences, Ås, Norway

${ }^{6}$ Centre for Ecosystems, Society and Biosecurity, Forest Research, Farnham, United Kingdom

${ }^{7}$ Department of Biochemistry, Genetics and Microbiology, Forestry and Agricultural Biotechnology Institute (FABI), University of Pretoria, Pretoria, South Africa

${ }^{8}$ Harper Adams University, Newport, Shropshire, United Kingdom

\subsection{Corresponding author}

* Centre for Research in Bioscience, Faculty of Health and Life Sciences, University of the West of England, Bristol, BS16 1QY, United Kingdom Tel: +441173284225 email: carrie.brady@uwe.ac.uk

\subsection{Keyword}

Rahnella, Yersiniaceae, bacterial decay, onion, Acute Oak Decline 


\subsection{Repositories:}

The GenBank/EMBL/DDBJ accession numbers are as follows: MW715676 - MW715683 (16S rRNA); MW699050 - MW699063 (atpD); MW699064 - MW699077 (gyrB); MW699078 - MW699091 (infB); MW699092 - MW699105 (rpoB); JAFMOS000000000 - JAFMPD000000000 (whole genome)

\section{ABSTRACT}

Bacteria isolated from onion bulbs suffering from bacterial decay in the United States and Norway were previously shown to belong to the genus Rahnella based on partial housekeeping gene sequences and/or fatty acid analysis. However, many strains could not be assigned to any existing Rahnella species. Additionally, strains isolated from creek water and oak as well as a strain with bioremediation properties were assigned to Rahnella based on partial housekeeping gene sequences. The taxonomic status of these 21 strains was investigated using multilocus sequence analysis, whole genome analyses, phenotypic assays and fatty acid analysis. Phylogenetic and phylogenomic analyses separated the strains into five clusters, one of which corresponded to Rahnella aceris. The remaining four clusters could be differentiated both genotypically and phenotypically from each other and existing Rahnella species. Based on these results, we propose the description of four novel species:

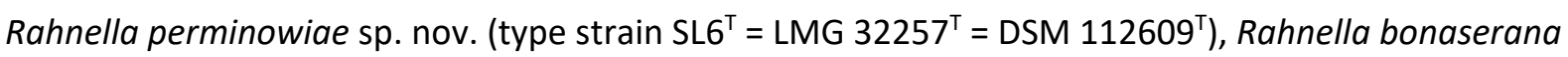
sp. nov. (type strain $\mathrm{H}_{11 b^{\top}}=\mathrm{LMG} 32256^{\top}=\mathrm{DSM} 112610^{\top}$ ), Rahnella rivi sp. nov. (type strain FC061912-

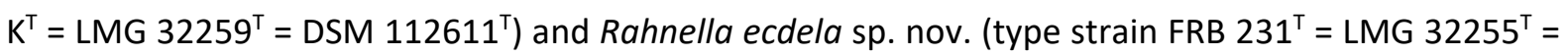
DSM $\left.112612^{\top}\right)$.

Rahnella is a genus of environmentally-linked species in the family Yersiniaceae [1]. For many years Rahnella aquatilis was the only validly described species in the genus Rahnella [2], although two genomospecies were proposed containing strains that could not be phenotypically differentiated from $R$. aquatilis [3]. $R$. aquatilis has long been acknowledged as a truly ubiquitous bacterium and has been isolated from a diverse range of sources, both environmental and clinical [4]. The genus Rahnella has expanded exponentially in recent years with the description of six novel species from a range of ecological niches and the elevation of the two genomospecies to validly described species [5-7]. These eight species contributed to the existing diversity of Rahnella with isolations of Rahnella victoriana, Rahnella variigena and Rahnella inusitata from bleeding cankers of oak; $R$. victoriana, $R$. variigena and $R$. woolbedingensis from asymptomatic alder and walnut; Rahnella bruchi from the gut of the Agrilus biguttatus beetle; Rahnella aceris and Rahnella laticis from sap of Acer pictum and Rahnella contaminans as a contaminant from MRSA agar plates [5-7]. In addition to their isolation from the 
natural environment, Rahnella species have been linked to nitrogen-fixation [8], metal and radionuclide sequestration [9] and biological control [10]; and more recently as possible pathogens of oak [11], poplar [12] and onion [13].

A study by Asselin et al. [13] indicated the existence of several potential novel Rahnella species, isolated over a number of years from onion bulbs with signs of bacterial decay in the United States and Norway, and from creek water in the United States. Multilocus sequence analysis of a selection of onion isolates placed them in four separate clusters without reference strains in the Rahnella genus, suggesting they belong to four novel taxa [13]. A further potential novel Rahnella taxon was identified in this study following gyrB gene sequencing of a strain previously isolated from a Quercus species displaying symptoms of Acute Oak Decline (AOD) in the Netherlands. The above mentioned strains were examined using a polyphasic approach based on genotypic, phenotypic, genomic and fatty acid assays to clarify their taxonomic position. Based on the results, we propose four novel Rahnella species: Rahnella perminowiae sp. nov., Rahnella bonaserana sp. nov., Rahnella rivi sp. nov. and Rahnella ecdela sp. nov.

\section{Isolation and Ecology}

Bacterial strains were previously isolated from onion bulbs in the United States (New York State and Oregon) and Norway (Vestfold, Østfold, Oppland and Hedmark) as described in Asselin et al. 2019 [13], either directly from onion tissue or following soaking and crushing in buffer or sterile water. Strain FC061912-K $\mathrm{K}^{\top}$ was isolated from creek water following high-speed centrifugation and culturing. A Rahnella strain Y9602 able to sequester metals was isolated from a mixed-waste-contaminated subsurface in Tennessee, United States [14]. FRB $231^{\top}$ was isolated from the bleeding lesion on a symptomatic oak in the Netherlands displaying symptoms of Acute Oak Decline (AOD). A swab was taken from the lesion, suspended in sterile Ringers solution and the resulting suspension plated onto Luria-Bertani (LB) agar. All strains can be routinely cultured on LB agar or in LB broth incubated at 28 ${ }^{\circ} \mathrm{C}$, and stored in $40 \%$ glycerol at $-80{ }^{\circ} \mathrm{C}$. See Suppl. Table S1 for a list of strains investigated in this study.

\section{Genotypic characterisation}

DNA for all PCR reactions was extracted using alkaline lysis [15] and stored at $-20{ }^{\circ} \mathrm{C}$. Multilocus sequence analysis (MLSA) was performed on strains which weren't included in the study by Asselin et 
al. [13], by amplification and sequencing of the $\operatorname{gyr} B, r p o B$, infB and $\operatorname{atp} D$ housekeeping genes as previously described [16]. The following modifications were used: annealing temperature of $46^{\circ} \mathrm{C}$ for the $g y r B$ PCR, alternative $r p o B$ amplification and sequencing primers designed for Rahnella species [13] and an alternative $a t p D$ reverse sequencing primer atpD-08R 5' CCCAGAAGTGCGGACACTTC 3'. Almost complete 16S rRNA gene sequencing was performed on a selection of strains (AR20, L31-1-12, $\mathrm{C} 60, \mathrm{SL6}^{\top}, \mathrm{H} 11 \mathrm{~b}^{\top}, \mathrm{FC} 061912-\mathrm{K}^{\top}$ and FRB $231^{\top}$ ) using the primers from Coenye et al. [17] and standard amplification cycles with an annealing temperature of $55{ }^{\circ} \mathrm{C}$. Additional sequences for the closest phylogenetic relatives were downloaded from GenBank and added to the datasets which were aligned and trimmed in BioEdit v7.2.5 [18] to the following lengths: gyrB - 741 bp, rpoB - 636 bp, infB - 615 bp, atpD - $642 \mathrm{bp}$ and 16S rRNA - $1346 \mathrm{bp}$. Following concatenation of the four housekeeping genes, Smart Model Selection (SMS) [19] was performed on both the MLSA and 16S rRNA gene datasets before maximum likelihood phylogenetic analysis using PhyML 3.0 [20]. Reliability of the generated clusters was assessed with 1000 bootstrap replicates.

In the maximum likelihood phylogenetic tree based on concatenated multilocus gene sequences (Fig. 1), the strains isolated from onion bulbs in the United States and Norway were separated into three clusters. The first cluster (Rahnella clade 1) comprised eight strains isolated from onion in the United States and Norway, strain Y9602 which can sequester heavy metals and the type strain of a recently described Rahnella species, $R$. aceris [6]. As the cluster was strongly supported with a bootstrap value of $100 \%$ and there was little sequence variation amongst the strains, it was concluded that strains in this cluster belonged to $R$. aceris. The remaining isolates from onion bulbs did not cluster with any reference or type strains. Rahnella clade 2, another large, well-supported group of nine strains from onion in the United States and Norway, clustered on the border of the type species, $R$. aquatilis, but was clearly separated and constituted a potential novel species. The remaining strain isolated from

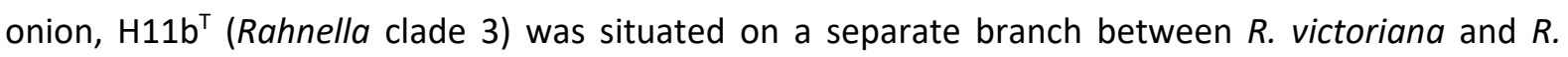
variigena. Strains FRB $231^{\top}$, isolated from Quercus sp. (Rahnella clade 4), and FC061912-K $\mathrm{K}^{\top}$ (Rahnella clade 5), isolated from creek water adjacent to an onion field, also had separate positions within the phylogenetic tree with no close association to a type strain indicating these three strains belonged to further novel Rahnella species.

The $16 \mathrm{~S}$ rRNA gene sequence pairwise similarity for the selected strains was calculated using EZBioCloud [21], and was $99.3 \%$ to $R$. aceris and $R$. aquatilis for strains from Rahnella clade 2; 99.2 $99.5 \%$ similar to $R$. variigena, $R$. bruchi, $R$. wooldbedingensis and $R$. victoriana for $\mathrm{H}^{1} 1 \mathrm{~b}^{\top}, \mathrm{FRB} 231^{\top}$ and FC061912-K K $^{\top}$ (Rahnella clades 3, 4 and 5). As expected and as previously observed [5-7], due to the 
recognised high degree of homogeneity in the 16S rRNA gene of genera in the Enterobacterales, the taxonomic position of the potential novel species was not clearly or reliably represented by the $16 \mathrm{~S}$ rRNA gene phylogenetic tree (Suppl. Fig. S1). The existing Rahnella species did not form a monophyletic clade and are interspersed by Rouxiella species and Ewingella americana.

BOX and ERIC PCR (repetitive element-based PCR) were performed on all isolates to examine their genetic diversity using the primers BOX-A1R and ERIC-2 and -1R, respectively [22]. Included in the analyses were two representative strains from each existing Rahnella species. Amplicons were separated in $1.5 \%$ agarose at $50 \mathrm{~V}$ for $\sim 3 \mathrm{~h}$. BOX PCR provided the best resolution for all strains tested and allowed the differentiation of the four potential novel species, not only from each other but also from existing Rahnella species (Suppl. Fig. S2). Although the fingerprint patterns for strains from Rahnella clade 2 had similar patterns, they were isolated from onion bulbs in different areas and countries and therefore cannot be clones.

\section{Genome features}

The whole genome sequences of nine strains isolated from symptomatic onion bulbs (Rahnella clade 1: AR20, F57b, L31-1-12, R92a; Rahnella clade 2: C60, L72c, L151-1A, SL6 ${ }^{\top}$ and Rahnella clade 3: H11b ${ }^{\top}$ ) and two single strains (Rahnella clades 4 and 5) from Quercus sp. (FRB 231 ${ }^{\top}$ ) and creek water (FC06191$\mathrm{K}^{\top}$ ) were sequenced by Microbes NG (Birmingham, UK) on the Illumina HiSeq platform, following DNA extraction by cell lysis and DNA purification with SPRI (Solid Phase Reversible Immobilization) beads. Reads were adapter trimmed using Trimmomatic 0.30 with a sliding window quality cutoff of Q15 [23]. De novo assembly was performed using SPAdes version 3.11.1 [24] and the resulting contigs were annotated in Prokka 1.11 [25]. Genome sizes from 5.40 to 5.75 Mbp and DNA G + C contents ranging from 51.4 to $53.2 \mathrm{~mol} \%$ were observed for the sequenced strains. The genome sequences were submitted to Genbank under the BioProject number PRJNA706176); genome features and assembly accessions are listed in Suppl. Table S2. The 16S rRNA sequences derived by genome sequencing of the above strains were compared to those obtained with Sanger sequencing to ensure there was no contamination of the whole genome sequences.

To infer the phylogenomic position of the strains, pairwise comparisons between the genomes were conducted using Genome Blast Distance Phylogeny (GBDP) and accurate intergenomic distances inferred under the algorithm 'trimming' and distance formula $d_{5}[26]$ with 100 distance replicates each. The resulting intergenomic distances were used to construct a balanced minimum evolution tree 
including Subtree Pruning and Regrafting (SPR) post-processing using FASTME 2.1.6.1 [27]. Branch support was inferred from 100 pseudo-bootstrap replicates and the tree was rooted at the midpoint 170 [28]. In the resulting phylogenomic tree (Fig. 2), all representative Rahnella strains from the present study formed a robust clade with existing Rahnella species with $100 \%$ bootstrap support. The clustering of the strains agreed with that observed in the MLSA phylogenetic tree (Fig. 1), with five strains assigned to the recently validated species $R$. aceris and four strains isolated from onion forming a separate cluster representing a novel taxon. The remaining representative strains from various sources had unique positions within the Rahnella clade confirming their taxonomic status as three novel species.

Whole genome comparisons were performed between representative Rahnella strains from the present study and existing Rahnella species using average nucleotide identity with FastANI [29]. Strains from Rahnella clade 1 shared ANI values of 98.2 to $99.7 \%$ with each other and 98.4 to $99.4 \%$ with the type strain of $R$. aceris SAP-19 $19^{\top}$ (Suppl. Table S3). These values are above the suggested species limit of $95 \%$ [30] confirming that the strains from onion and strain Y9602 belong to the same taxon, $R$. aceris. ANI values ranging from 99.1 - $99.3 \%$ were observed amongst strains from Rahnella clade 2 confirming they belong to a single taxon. The strains from the three single-strain species (Rahnella clades $3-5$ ) exhibited ANI values of less than $91.2 \%$ to each other, and to strains from Rahnella clade 2. Furthermore, representative strains from Rahnella clades $2-5$ were less than $94 \%$ related in terms of ANI to all existing Rahnella species (Table 1). The conclusions drawn from ANI analysis were confirmed by in silico DNA-DNA hybridisation (is DDH) using the genome-to-genome distance calculator (GGDC) [26] and are also presented in Table 1.

\section{Physiology and Chemotaxonomy}

Cell size, morphology and motility were determined using light microscopy and the microscopy imaging software CellSens version 1.11 (Olympus Life Science, Tokyo, Japan). Flagella arrangement for all proposed species, and existing Rahnella species (except $R$. contaminans and $R$. laticis) was observed by transmission electron microscopy (FEI Tecnai 12 120kV BioTwin Spirit TEM) following negative staining. Briefly, grids were floated on mid-log phase bacterial suspensions for 2 mins, washed 3 times in distilled water, stained with $3 \%$ uranyl acetate for $30 \mathrm{sec}$ and washed again 3 times before wicking away excess liquid and air drying. Colony morphology was examined following growth on tryptone soya agar (TSA, Sigma) incubated at $28{ }^{\circ} \mathrm{C}$ for $48 \mathrm{~h}$, while the growth temperature range was determined on TSA incubated at 4, 10, 25, 28, 30, 37 and $41^{\circ} \mathrm{C}$ in triplicate. Ranges for $\mathrm{pH}$ were tested in triplicate in tryptone soya broth (TSB, Oxoid) with the $\mathrm{pH}$ adjusted to $4-10$ (in increments of 1 ) 
with sodium acetate/acetic acid and carbonate/bicarbonate buffers. Salt tolerance was tested in saline-free nutrient broth ( $3 \mathrm{~g} \mathrm{l}^{-1}$ beef extract, $5 \mathrm{~g} \mathrm{l}^{-1}$ peptone) with the salt concentration adjusted to $1-7 \%$ (in increments of $1 \% \mathrm{w} / \mathrm{v}$ ) by supplemented $\mathrm{NaCl}$. These were incubated overnight at $28^{\circ} \mathrm{C}$ with shaking. Included in the temperature, $\mathrm{pH}$ and salt tolerance tests were the type strains for existing Rahnella species (except R. aceris, R. contaminans and R. laticis). Catalase and oxidase activity were determined by bubble production in $3 \% \mathrm{v} / \mathrm{v} \mathrm{H}_{2} \mathrm{O}_{2}$ and staining with Kovács reagent (1 \% tetramethyl-p-phenylenediamine dihydrochloride), respectively.

Cells from all strains are straight rods with an average size of $0.6 \times 1.6 \mu \mathrm{m}$. They occur singly, or in pairs and are motile by peritrichous flagella (Fig. 3). Members of the order Enterobacterales are known for their motility by several peritrichous flagella, and a recent study confirmed that all examined Rahnella species possess the primary peritrichous flagella locus (flag-1), with most strains of $R$. variigena encoding an additional secondary predicted peritrichous locus (flag-3b) [31]. However, the recently described $R$. aceris, $R$. contaminans and $R$. laticis are indicated to be motile by a single, polar flagellum $[6,7]$ and it was suggested that as all Rahnella species have similar flagella gene profiles, they could all be motile by a polar flagellum [7]. The original description of the genus Rahnella describes $R$. aquatilis as motile by peritrichous flagella, although electron microscopy images were not published [2,4]. To clarify the flagella arrangement of the existing Rahnella species, strains of these were also imaged by TEM as described above (with the exception of $R$. contaminans and $R$. laticis). All species examined clearly displayed multiple flagella on the surface of the cells, not at the poles, providing evidence that the majority of Rahnella species are motile by peritrichous flagella (Suppl. Fig. S3). Additionally, the genomes of all existing Rahnella species and the proposed four novel species were screened for the presence of flag loci. All species were found to possess the primary peritrichous flagella locus (flag-1), while the additional secondary flag-3b locus was encoded in the genome of

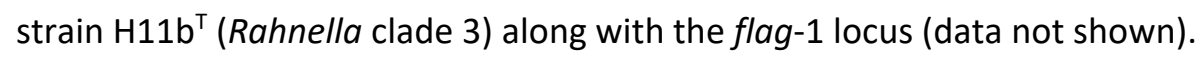

Following growth on TSA for $48 \mathrm{~h}$, the resulting colonies are cream-coloured, round, slightly convex, smooth with entire margins and $2-3 \mathrm{~mm}$ in diameter. All strains tested grew at 4, 10, 25, 28, 30 and $37{ }^{\circ} \mathrm{C}$ but not at $41^{\circ} \mathrm{C}$. Growth for all Rahnella strains included in this study was observed in the $\mathrm{pH}$ range of 5 to 8 , with weak growth at $\mathrm{pH} 9$. Strains from the four proposed novel species and existing Rahnella species grew well in nutrient broth supplemented with up to $6 \% \mathrm{NaCl}$, while weak growth was observed at $7 \% \mathrm{NaCl}$. All strains from the proposed novel species are oxidase negative and catalase positive. 
Phenotypic testing was performed on a selection of strains from Rahnella aceris (AR20, C1b, F57b, L31-1-12, L172-1A, R92a and Y9602), Rahnella clade 2 (A66, C60, L72C, L51-1-12, L151-1A, L173-1B

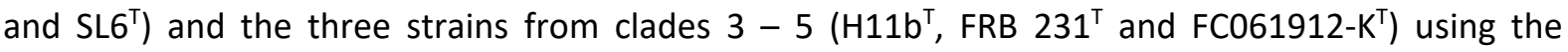
commercial assays API 20E, API 50 CH/B (bioMérieux) and GEN III GN/GP microplates (Biolog). These were performed according to the manufacturer's instructions. GEN III plates were scored after $6 \mathrm{~h}$ and again after 24 h, while API 20 E and 50CH/B galleries were read after 24 h and 24 - 48 h, respectively. The type strain of R. aquatilis, LMG $2794^{\top}$, was included as a positive control in the API 20E and 50 $\mathrm{CH} / \mathrm{B}$ tests. Due to a lack of phenotypic data for existing Rahnella species based on the GEN III microplate system, the type strains and reference strains for these were included in the GEN III assays (with the exception of the type strains of R. aceris, R.contaminans and R. laticis).

Strains from the four proposed novel species were clearly differentiated from each other, and from the existing species in the genus Rahnella based on phenotypes. Even the three proposed single-strain species have clearly distinguishable phenotypic profiles. The most useful phenotypic characteristics for species differentiation are listed in Table 2. The full phenotypic profiles for each proposed species are described in the below protologues. It is acknowledged that the phenotypic profiles for the singlestrain species may change as further strains belonging to these taxa are isolated. Differing results for several phenotypic characteristics for existing Rahnella species were observed by Jeon et al. [7], such as citrate utilization, arginine dihydrolase, gelatinase and acetoin production. The phenotypic data generated in the present study and previous studies $[5,6]$ were obtained following the manufacturer's instructions for incubation temperature and time, whereas the data presented by Jeon et al. was generated under different incubation conditions. This could account for the differences observed between the studies.

259

Fatty acid methyl ester (FAME) analysis was performed on selected strains from Rahnella clade 1, now confirmed as belonging to $R$. aceris (AR20, L31-1-12, R92a and Y9602), clade 2 (C60, L72C, L151-1A and

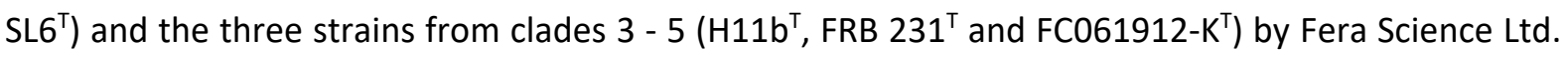
(York, UK). Strains were cultivated on TSA at $28^{\circ} \mathrm{C}$ for $24 \mathrm{~h}$ and the protocol followed was based on the Sherlock Microbial Identification System Version 6.4 (MIDI Inc.). The results obtained were compared against the library RTSBA6 6.21. The fatty acid profiles obtained for all strains were similar in composition to those of existing Rahnella species [5,6]. Complete fatty acid profiles for all Rahnella species are presented in Table 3. 
In the past eight years, the genus Rahnella has evolved from a monotypic genus to a genus comprising species from a diverse range of hosts, sources and locations. The description of four novel Rahnella species contributes to an already extensive list of environmental niches and highlights a possible role for several species in bacterial decay of onion and AOD. Additionally, a large number of strains from onion bulb decay in the USA and Norway have been assigned to $R$. aceris, along with strain Y9602 that has the ability to sequester heavy metals, enhancing the description of this former single-strain species.

Based on the genotypic, genomic, phenotypic and chemotaxonomic data generated in this study, we conclude that the strains represent four novel species and propose the description of: Rahnella perminowiae sp. nov. (type strain SL6 ${ }^{\top}=\mathrm{LMG} 32257^{\top}=\mathrm{DSM} 112609^{\top}$ ), Rahnella bonaserana sp. nov. (type strain $\left.=\mathrm{H}_{11 \mathrm{~b}^{\top}}=\mathrm{LMG} 32256^{\top}=\mathrm{DSM} 112610^{\top}\right)$, Rahnella rivi sp. nov. (type strain $=\mathrm{FC061912}-\mathrm{K}^{\top}$

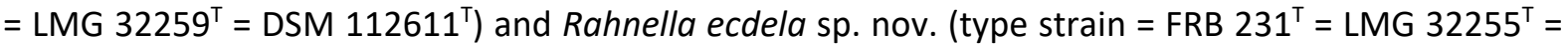
DSM $\left.112612^{\top}\right)$.

\section{Description of Rahnella perminowiae sp. nov.}

Rahnella perminowiae (per.mi.no'wi.ae. N.L. gen. fem. n. perminowiae, pertaining to Perminow, named after Juliana I.S. Perminow for her work on bacterial plant diseases, including diseases of onion, at the Norwegian Institute of Bioeconomy Research since 1993).

Gram-negative rods $(0.6-0.8 \times 1.5-1.8 \mu \mathrm{m})$ which occur singly or in pairs and are motile. Colonies are cream on tryptone soya agar, round, convex and smooth with entire margins, facultatively anaerobic, oxidase negative and catalase positive. Optimum growth is at $28^{\circ} \mathrm{C}$, although strains can grow within the range $4-37^{\circ} \mathrm{C}$. Strains grow well at pH $5-8$ and in broth supplemented with $\mathrm{NaCl}$ up to $6 \%$. Positive for $\beta$-galactosidase, arginine dihydrolase and citrate utilization. Negative for lysine decarboxylase, ornithine decarboxylase, $\mathrm{H}_{2} \mathrm{~S}$, urease, tryptophan deaminase, indole production, acetoin production and gelatinase. Nitrate is reduced to nitrite. Acid is produced from: glycerol, Larabinose, D-ribose, D-xylose, D-galactose, D-glucose, D-fructose, D-mannose, L-rhamnose, dulcitol, D-mannitol, D-sorbitol, $\mathrm{N}$-acetylglucosamine, methyl- $\alpha \mathrm{D}$-glucopyranoside, arbutin, esculin ferric citrate, salicin, D-cellobiose, D-maltose, D-lactose, D-melibiose, D-saccharose, D-trehalose, Draffinose, gentiobiose, D-fucose and L-fucose (API 50CHB/E). Dextrin, D-maltose, D-trehalose, Dcellobiose, gentiobiose, sucrose, D-raffinose, $\alpha$-D-lactose, D-melibiose, $\beta$-methyl-D-glucoside, D- 
galactose, D-fucose, L-fucose, L-rhamnose, D-sorbitol, D-mannitol, glycerol, $\alpha$-D-glucose-6-phosphate, $\beta$-D-fructose-6-phosphate, glycyl-L-proline, L-alanine, L-aspartic acid, L-glutamic acid, L-histidine, Lserine, pectin, D-galacturonic acid, L-galactonic acid lactone, D-gluconic acid, D-glucuronic acid, glucuronamide, mucic acid, quinic acid, D-saccharic acid, methyl pyruvate, citric acid, L-malic acid, bromosuccinic acid, acetic acid and formic acid are utilised (Biolog GEN III). L-lactic acid and $\alpha$ ketoglutaric acid are variable (type strain is weakly positive). Major fatty acids include $C_{16: 0}, C_{18: 1} \omega 7 c$, $C_{17: 0}$ cyclo, summed feature 2 (iso- $C_{16: 1}$ and/or $C_{14: 0} 3-O H$ ) and summed feature 3 ( $C_{16: 1} \omega 7 c$ and /or iso$\mathrm{C}_{15: 0}$ 2-OH).

The DNA G + C content of the type strain is $51.8 \mathrm{~mol} \%$.

The type strain SL6 ${ }^{\top}\left(=\right.$ LMG $32257^{\top}=$ DSM $\left.112609^{\top}\right)$ was isolated from onion in Hedmark, Norway.

\section{Description of Rahnella bonaserana sp. nov.}

Rahnella bonaserana (bo.na.se.ra'na. N.L. fem. adj. bonaserana, pertaining to Bonasera, named after Jean M. Bonasera for her work on bacterial plant diseases at Cornell University over 22 years developing culturing and identification techniques)

Gram-negative rods $(0.5-0.6 \times 1.3-1.6 \mu \mathrm{m})$ which occur singly or in pairs and are motile. Colonies are cream on tryptone soya agar, round, convex and smooth with entire margins, facultatively anaerobic, oxidase negative and catalase positive. Optimum growth is at $28^{\circ} \mathrm{C}$, although strains can grow within the range $4-37^{\circ} \mathrm{C}$. Strains grow well at pH $5-8$ and in broth supplemented with $\mathrm{NaCl}$ up to $6 \%$. Positive for $\beta$-galactosidase, arginine dihydrolase and citrate utilization. Negative for lysine decarboxylase, ornithine decarboxylase, $\mathrm{H}_{2} \mathrm{~S}$, urease, tryptophan deaminase, indole production, acetoin production and gelatinase. Nitrate is reduced to nitrite. Acid is produced from: glycerol, Larabinose, D-ribose, D-xylose, D-galactose, D-glucose, D-fructose, D-mannose, L-rhamnose, dulcitol, D-mannitol, D-sorbitol, arbutin, esculin ferric citrate, salicin, D-cellobiose, D-maltose, D-lactose, Dmelibiose, D-saccharose, D-trehalose, D-raffinose, D-fucose and L-fucose (API 50CHB/E). Dextrin, Dmaltose, D-trehalose, D-cellobiose, gentiobiose, sucrose, D-raffinose, $\alpha$-D-lactose, D-melibiose, $\beta$ methyl-D-glucoside, D-salicin, $N$-acetyl-D-glucosamine, $N$-acetyl- $\beta$-D-mannosamine, $N$-acetyl neuraminic acid, $\alpha$-D-glucose, D-mannose, D-fructose, D-galactose, 3-methyl glucose, D-fucose, Lfucose, L-rhamnose, inosine, D-sorbitol, D-mannitol, glycerol, $\alpha$-D-glucose-6-phosphate, $\beta$-D-fructose6-phosphate, D-aspartic acid, D-serine, glycyl-L-proline, L-alanine, L-aspartic acid, L-glutamic acid, Lhistidine, L-serine, pectin, D-galacturonic acid, L-galactonic acid lactone, D-gluconic acid, D-glucuronic acid, glucuronamide, mucic acid, quinic acid, D-saccharic acid, methyl pyruvate, L-lactic acid, citric 
acid, L-malic acid, acetic acid and formic acid are utilised (Biolog GEN III). Major fatty acids include $\mathrm{C}_{16: 0}$ and $\mathrm{C}_{17: 0}$ cyclo.

The DNA G + C content of the type strain is $51.9 \mathrm{~mol} \%$. The type strain $\mathrm{H}^{11 \mathrm{~b}^{\top}}$ (= LMG $32256^{\top}=\mathrm{DSM} 112610^{\top}$ ) was isolated from onion in New York State, USA.

\section{Description of Rahnella rivi sp. nov.}

342

343

344

345

346

347

348

Rahnella rivi (ri'vi. L. gen. n. rivi, of a river or creek, referring to the isolation source of the type strain)

Gram-negative rods $(0.6-0.7 \times 1.5-1.8 \mu \mathrm{m})$ which occur singly or in pairs and are motile. Colonies are cream on tryptone soya agar, round, convex and smooth with entire margins, facultatively anaerobic, oxidase negative and catalase positive. Optimum growth is at $28{ }^{\circ} \mathrm{C}$, although strains can grow within the range $4-37^{\circ} \mathrm{C}$. Strains grow well at pH $5-8$ and in broth supplemented with $\mathrm{NaCl}$ up to $6 \%$. Positive for $\beta$-galactosidase, arginine dihydrolase and acetoin production. Negative for lysine decarboxylase, ornithine decarboxylase, citrate utilization, $\mathrm{H}_{2} \mathrm{~S}$, urease, tryptophan deaminase, indole production and gelatinase. Nitrate is reduced to nitrite. Acid is produced from: glycerol, L-arabinose, D-ribose, D-xylose, D-galactose, D-glucose, D-fructose, D-mannose, L-rhamnose, dulcitol, D-mannitol, methyl- $\alpha \mathrm{D}$-glucopyranoside, arbutin, esculin ferric citrate, salicin, D-cellobiose, D-maltose, D-lactose, D-melibiose, D-saccharose, D-trehalose, D-raffinose, gentiobiose and D-turanose (API 50CHB/E). Dextrin, D-maltose, D-trehalose, D-cellobiose, gentiobiose, sucrose, D-turanose, stachyose, Draffinose, $\alpha$-D-lactose, D-melibiose, $\beta$-methyl-D-glucoside, D-salicin, $N$-acetyl-D-glucosamine, $N$ acetyl- $\beta$-D-mannosamine, $N$-acetyl neuraminic acid, $\alpha$-D-glucose, D-mannose, D-fructose, Dgalactose, D-fucose, L-fucose, L-rhamnose, inosine, D-mannitol, glycerol, $\alpha$-D-glucose-6-phosphate, $\beta$ D-fructose-6-phosphate, D-aspartic acid, D-serine, glycyl-L-proline, L-alanine, L-aspartic acid, Lglutamic acid, L-histidine, L-serine, pectin, D-galacturonic acid, L-galactonic acid lactone, D-gluconic acid, D-glucuronic acid, glucuronamide, mucic acid, D-saccharic acid, L-lactic acid, citric acid, L-malic acid, tween 40, acetoacetic acid, acetic acid and formic acid are utilised (Biolog GEN III). Major fatty acids include $C_{16: 0}, C_{18: 1} \omega 7 c, C_{17: 0}$ cyclo, summed feature 2 (iso- $C_{16: 1}$ and/or $C_{14: 0} 3-O H$ ) and summed feature $3\left(C_{16: 1} \omega 7 c\right.$ and /or iso- $\left.C_{15: 0} 2-O H\right)$.

The DNA G + C content of the type strain is $53.2 \mathrm{~mol} \%$.

The type strain FC061912-K $\mathrm{K}^{\top}$ (= LMG $32259^{\top}=\mathrm{DSM} 112611^{\top}$ ) was isolated from river water in New York State, USA. 


\section{Description of Rahnella ecdela sp. nov.}

Rahnella ecdela (ec.de'la. N.L. fem. adj. ecdela from Gr. adj. ekdélos meaning clear or manifest, referring to the clear separation from other species in this genus)

Gram-negative rods $(0.5-0.6 \times 1.3-1.5 \mu \mathrm{m})$ which occur singly or in pairs and are motile. Colonies are cream on tryptone soya agar, round, convex and smooth with entire margins, facultatively anaerobic, oxidase negative and catalase positive. Optimum growth is at $28^{\circ} \mathrm{C}$, although strains can grow within the range $4-37^{\circ} \mathrm{C}$. Strains grow well at pH $5-8$ and in broth supplemented with $\mathrm{NaCl}$ up to $6 \%$. Positive for $\beta$-galactosidase. Negative for arginine dihydrolase, lysine decarboxylase, ornithine decarboxylase, citrate utilization, $\mathrm{H}_{2} \mathrm{~S}$, urease, tryptophan deaminase, indole production, acetoin production and gelatinase. Nitrate is reduced to nitrite. Acid is produced from: glycerol, L-arabinose, D-ribose, D-xylose, D-galactose, D-glucose, D-fructose, D-mannose, L-rhamnose, dulcitol, D-mannitol, $\mathrm{N}$-acetylglucosamine, arbutin, esculin ferric citrate, salicin, D-cellobiose, D-maltose, D-lactose, Dmelibiose, D-saccharose, D-trehalose, D-raffinose, gentiobiose, D-fucose, L-fucose and D-arabitol (API $50 \mathrm{CHB} / \mathrm{E})$. Dextrin, D-maltose, D-trehalose, D-cellobiose, gentiobiose, sucrose, D-raffinose, $\alpha-D$ lactose, D-melibiose, $\mathrm{D}$-salicin, $\mathrm{N}$-acetyl-D-glucosamine, $\mathrm{N}$-acetyl- $\beta$-D-mannosamine, $N$-acetyl-Dgalactosamine, $\alpha$-D-glucose, D-mannose, D-fructose, D-galactose, 3-methyl glucose, D-fucose, Lfucose, L-rhamnose, inosine, D-mannitol, D-arabitol, glycerol, $\alpha$-D-glucose-6-phosphate, $\beta$-D-fructose6-phosphate, D-aspartic acid, D-serine, glycyl-L-proline, L-alanine, L-aspartic acid, L-glutamic acid, Lhistidine, L-serine, pectin, D-galacturonic acid, L-galactonic acid lactone, D-gluconic acid, D-glucuronic acid, glucuronamide, mucic acid, quinic acid, D-saccharic acid, L-lactic acid, citric acid, L-malic acid, tween 40, acetoacetic acid, acetic acid and formic acid are utilised (Biolog GEN III). Major fatty acids include $\mathrm{C}_{16: 0}, \mathrm{C}_{17: 0}$ cyclo and summed feature 2 .

The DNA G + C content of the type strain is $51.9 \mathrm{~mol} \%$.

The type strain FRB $231^{\top}$ (= LMG $32255^{\top}=$ DSM $112612^{\top}$ ) was isolated from Quercus spp. exhibiting AOD symptoms in the Netherlands.

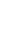

.

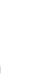

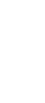

1


Rahnella (Rah.nel'la. N.L. dim. ending -ella; N.L. fem n. Rahnella named after Otto Rahn, the GermanAmerican microbiologist who proposed the name Enterobacteriaceae in 1937)

408

The description is based on the data from Brenner et al. 1998 [3], Kämpfer, 2005 [4], Brady et al. 2014 [5], Lee et al. 2020 [6], Jeon et al. 2021 [7] and this study.

Gram-negative straight rods $(0.5-1.0 \times 1.0-3.0 \mu \mathrm{m})$, facultatively anaerobic, oxidase negative and catalase positive. Cells occur singly or in pairs and are motile by peritrichous flagella when grown at $25{ }^{\circ} \mathrm{C}$, although some species possess a single flagellum. Colonies are white to cream on nutrient or tryptone soya agar, round, slightly convex and smooth with entire margins. Strains can grow at temperatures between 4 and $30{ }^{\circ} \mathrm{C}$ with optimum growth at $28-30{ }^{\circ} \mathrm{C}$, growth at $37{ }^{\circ} \mathrm{C}$ varies depending on the species. Strains can grow within the $\mathrm{pH}$ range $5-8$ and in the presence of $0-6 \%$ (w/v) NaCl. Positive for $\beta$-galactosidase activity but negative for $\mathrm{H}_{2} \mathrm{~S}$, urease and indole production. Lysine decarboxylase, ornithine decarboxylase and tryptophan deaminase activity are all negative. Arginine dihydrolase, citrate utilization, acetoin and gelatinase production are variable. Nitrate is reduced to nitrite. Acid is produced from: L-arabinose, D-ribose, D-xylose, D-galactose, D-glucose, Dfructose, D-mannose, L-rhamnose, D-mannitol, arbutin, esculin ferric citrate, salicin, D-cellobiose, Dmaltose, D-lactose, D-melibiose and D-trehalose. The following carbon sources are utilized at $28^{\circ} \mathrm{C}$ : D-maltose, $N$-acetyl-D-glucosamine, $\alpha$-D-glucose, D-mannose. Frequently isolated from fresh water and various environmental habitats including soils, the rhizosphere, woody tissues of oak, alder and walnut, tree sap and onion bulbs. Also found in the intestines of snails and insects such as beetles and moths. Can be isolated from foods or human clinical specimens, especially from immunocompromised patients. Major fatty acids include $C_{16: 0}$ and $C_{17: 0}$ cyclo. The presence of $\mathrm{C}_{18: 1} \omega 7 c$, summed feature 2 (iso- $\mathrm{C}_{16: 1}$ and/or $\mathrm{C}_{14: 0} 3-\mathrm{OH}$ ) and summed feature 3 $\left(C_{16: 1} \omega 7 c\right.$ and /or iso- $\left.C_{15: 0} 2-O H\right)$ as major fatty acids is variable.

The $\mathrm{G}+\mathrm{C}$ content ranges from 51.3 to $53.7 \mathrm{~mol} \%$. The type species is Rahnella aquatilis. 


\subsection{Authors and contributors}

CB was involved in the conceptualisation, data curation, formal analysis, investigation, methodology, validation, visualisation, writing, reviewing and editing of the work. JA, SB, MB, BC and SV were involved in the provision of resources and the conceptualisation, writing, reviewing and editing of the manuscript. DA and SD were responsible for funding acquisition and the conceptualisation, writing, reviewing and editing of the manuscript.

447

\subsection{Conflicts of interest and disclaimers}

449 The authors declare that there are no conflicts of interest.

450 Mention of trade names or commercial products in this publication is solely for the purpose of 451 providing specific information and does not imply recommendation or endorsement by the U.S. Department of Agriculture. USDA is an equal opportunity provider and employer.

\subsection{Funding information}

This research was supported by the UK Research and Innovation's (UKRI) Strategic Priorities Fund (SPF) programme on Bacterial Plant Diseases (grant BB/T010886/1) funded by the Biotechnology and Biological Sciences Research Council (BBSRC), the Department for Environment, Food and Rural Affairs (Defra), the Natural Environment Research Council (NERC) and the Scottish Government. CB received additional funding from Woodland Heritage, BC and SD received funding from the Forestry Commission.

\subsection{Acknowledgements}

The authors would like to thank Dr Maria Chuvochina for assisting with the etymology of the novel species, Angeliki Savvantoglou for discussions on Greek translations and Dr Dann Turner for discussions on genome analyses and electron microscopy. We gratefully acknowledge the Wolfson Bioimaging Facility, especially Dr Lorna Hodgson, for assistance with the electron microscopy as well as the National Reference Centre (NRC) of the Netherlands Food and Consumer Product Safety Authority (NVWA) for the provision of the samples from symptomatic Quercus. Genome sequencing was provided by MicrobesNG (http://www.microbesng.uk) which is supported by the BBSRC (grant number BB/L024209/1). 
1. Adeolu M, Alnajar S, Naushad S, Gupta RS. Genome-based phylogeny and taxonomy of the Enterobacteriaceae, Erwiniaceae fam. nov., Pectobacteriaceae fam. nov., Yersiniaceae fam. nov., Hafniaceae fam. nov., Morganellaceae fam. nov., and Budviciacceae fam. nov. Int I Syst Evol Microbiol 2016;66:5575-5599.

2. Izard D, Gavini F, Trinel PA, Leclerc H. Rahnella aquatilis, nouveau membre de la famille des Enterobacteriaceae. Ann Microbiol 1979;130:163-177.

3. Brenner DJ, Müller HE, Steigerwalt AG, Whitney AM, O'Hara CM, et al. Two new Rahnella genomospecies that cannot be phenotypically differentiated from Rahnella aquatilis. Int J Syst Bacteriol 1998;48:141-149.

4. Kämpfer P. Rahnella . Bergey's Man Syst Archaea Bact 2015;1-16.

5. Brady C, Hunter G, Kirk S, Arnold D, Denman S. Rahnella victoriana sp. nov., Rahnella bruchi sp. nov., Rahnella woolbedingensis sp. nov., classification of Rahnella genomospecies 2 and 3 as Rahnella variigena sp. nov. and Rahnella inusitata sp. nov., respectively and emended description of the genus Rahnella. Syst Appl Microbiol 2014;37:545-552.

6. Lee SD, Jeon D, Kim IS, Choe H, Kim JS. Rahnella aceris sp. nov., isolated from sap drawn from Acer pictum. Arch Microbiol 2020;202:2411-2417.

7. Jeon D, Kim IS, Lee SD. Rahnella laticis sp. nov. and Rahnella contaminans sp. nov., and emended description of the genus Rahnella. Int J Syst Evol Microbiol;71. Epub ahead of print 2021. DOI: $10.1099 / \mathrm{ijsem} .0 .004893$.

8. Berge O, Heulin T, Achouak W, Richard C, Bally R, et al. Rahnella aquatilis, a nitrogen-fixing enteric bacterium associated with the rhizosphere of wheat and maize. Canadian journal of microbiology 1991; v. 37:195-203.

9. Martinez RJ, Bruce D, Detter C, Goodwin LA, Han J, et al. Complete genome sequence of Rahnella sp. strain y9602, a gammaproteobacterium isolate from metal- and radionuclidecontaminated soil. J Bacteriol 2012;194:2113-2114.

10. Chen F, Li J-Y, Guo Y-B, Wang J-H, Wang H-M. Biological control of grapevine crown gall: purification and partial characterisation of an antibacterial substance produced by Rahnella aquatilis strain HX2. Eur J Plant Pathol 2009;124:427-437.

11. Doonan J, Denman S, Pachebat JA, McDonald JE. Genomic analysis of bacteria in the Acute 
Oak Decline pathobiome. Microb Genomics 2019;5:0-15.

12. Moradi-Amirabad Y, Khodakaramian G. First report of bleeding canker caused by Rahnella sp. on Populus nigra in Iran. New Dis Reports 2020;41:37.

13. Asselin JE, Eikemo H, Perminow J, Nordskog B, Brurberg MB, et al. Rahnella spp. are commonly isolated from onion (Allium cepa) bulbs and are weakly pathogenic. J Appl Microbiol 2019;127:812-824.

14. Martinez RJ, Wang Y, Raimondo MA, Coombs JM, Barkay T, et al. Horizontal gene transfer of PIB-type ATPases among bacteria isolated from radionuclide- and metal-contaminated subsurface soils. Appl Environ Microbiol 2006;72:3111-3118.

15. Niemann S, Pühler A, Tichy H V., Simon R, Selbitschka W. Evaluation of the resolving power of three different DNA fingerprinting methods to discriminate among isolates of a natural Rhizobium meliloti population. J Appl Microbiol 1997;82:477-484.

16. Brady C, Cleenwerck I, Venter S, Vancanneyt M, Swings J, et al. Phylogeny and identification of Pantoea species associated with plants, humans and the natural environment based on multilocus sequence analysis (MLSA). Syst Appl Microbiol 2008;31:447-460.

17. Coenye T, Falsen E, Vancanneyt M, Hoste B, Govan JRW, et al. Classification of Alcaligenes faecalis-like isolates from the environment and human clinical samples as Ralstonia gilardii sp. nov. Int J Syst Bacteriol 1999;49:405-413.

18. Hall TA. BioEdit: a user-friendly biological sequence alignment editor and analysis program for Windows 95/98/NT. In: Nucleic acids symposium series. 1999. pp. 95-98.

19. Lefort V, Longueville J-E, Gascuel O. SMS: Smart Model Selection in PhyML. Mol Biol Evol 2017;34:2422-2424.

20. Guindon S, Dufayard JF, Lefort V, Anisimova M, Hordijk W, et al. New algorithms and methods to estimate maximum-likelihood phylogenies: Assessing the performance of PhyML 3.0. Syst Biol 2010;59:307-321.

21. Yoon S, Ha S, Kwon S, Lim J, Kim Y, et al. Introducing EzBioCloud : a taxonomically united database of 16S rRNA gene sequences and whole-genome assemblies. 2019;1613-1617.

22. Versalovic J, Schneider M, de Bruijn F, Lupski JR. Genomic fingerprinting of bacteria using repetitive sequence-based polymerase chain reaction. Methods Mol Cell Biol 1994;5:25-40.

23. Bolger AM, Lohse M, Usadel B. Trimmomatic: A flexible trimmer for Illumina sequence data. Bioinformatics 2014;30:2114-2120.

24. Nurk S, Bankevich A, Antipov D, Gurevich A, Korobeynikov A, et al. Assembling genomes and mini-metagenomes from highly chimeric reads. In: Lecture Notes in Computer Science (including subseries Lecture Notes in Artificial Intelligence and Lecture Notes in 

Bioinformatics). 2013. pp. 158-170.

$54025 . \quad$ Seemann T. Prokka: rapid prokaryotic genome annotation. Bioinformatics 2014;30:20682069.

26. Meier-Kolthoff JP, Auch AF, Klenk H-P, Göker M. Genome sequence-based species delimitation with confidence intervals and improved distance functions. BMC Bioinformatics 2013;14:60.

27. Lefort V, Desper R, Gascuel O. FastME 2.0: A Comprehensive, Accurate, and Fast DistanceBased Phylogeny Inference Program. Mol Biol Evol 2015;32:2798-2800.

547 28. Farris JS. Estimating Phylogenetic Trees from Distance Matrices. Am Nat 1972;106:645-668.

548 29. Jain C, Rodriguez-R LM, Phillippy AM, Konstantinidis KT, Aluru S. High throughput ANI analysis of $90 \mathrm{~K}$ prokaryotic genomes reveals clear species boundaries. Nat Commun 2018;9:5114.

551 30. Goris J, Konstantinidis KT, Klappenbach JA, Coenye T, Vandamme P, et al. DNA-DNA hybridization values and their relationship to whole-genome sequence similarities. Int I Syst Evol Microbiol 2007;57:81-91.

31. De Maayer P, Pillay T, Coutinho TA. Flagella by numbers: Comparative genomic analysis of the supernumerary flagellar systems among the Enterobacterales. BMC Genomics 2020;21:116. 
Table 1: Percentages of average nucleotide identity (fastANI - lower left, orange) and in silico DNA-DNA hybridization (isDDH - upper right, blue) between strain columns are shaded in grey). Percentages above cut-off value for species delimitation (>95 \% for ANI and >70 \% for isDDH) are shaded.

563

\begin{tabular}{|c|c|c|c|c|c|c|c|c|c|c|c|c|c|c|c|c|}
\hline isDDH & 1 & 2 & 3 & 4 & 5 & 6 & 7 & 8 & 9 & 10 & 11 & 12 & 13 & 14 & 15 & 16 \\
\hline 1 & 100 & 96.2 & 93.4 & 93.9 & 32.2 & 28.2 & 31.6 & 49.2 & 42.3 & 31.4 & 28.6 & 25.3 & 28.2 & 32.8 & 33.9 & 31.6 \\
\hline 2 & 99.3 & 100 & 93.1 & 93.6 & 31.7 & 27.8 & 31.2 & 45.0 & 41.8 & 31.1 & 28.3 & 26.5 & 27.9 & 32.4 & 33.8 & 31.2 \\
\hline 3 & 99.1 & 99.1 & 100 & 94.4 & 31.8 & 27.7 & 31.2 & 44.8 & 41.8 & 31.0 & 28.3 & 26.5 & 27.8 & 32.4 & 33.7 & 31.2 \\
\hline 4 & 99.2 & 99.1 & 99.3 & 100 & 31.9 & 27.9 & 31.3 & 45.1 & 42.0 & 31.3 & 28.4 & 26.6 & 28.1 & 32.6 & 33.8 & 31.3 \\
\hline 5 & 87.4 & 87.8 & 87.8 & 87.8 & 100 & 28.8 & 42.8 & 34.1 & 34.1 & 42.1 & 29.9 & 26.0 & 28.9 & 54.8 & 33.2 & 42.2 \\
\hline 6 & 85.5 & 86.4 & 86.3 & 86.4 & 86.3 & 100 & 28.6 & 29.0 & 28.7 & 28.5 & 27.8 & 31.7 & 27.8 & 29.2 & 28.8 & 28.7 \\
\hline 7 & 87.1 & 87.5 & 87.5 & 87.6 & 91.2 & 86.2 & 100 & 33.3 & 33.2 & 53.5 & 29.6 & 25.4 & 28.7 & 44.3 & 33.2 & 47.6 \\
\hline 8 & 91.7 & 91.6 & 91.6 & 91.6 & 88.4 & 86.3 & 88.0 & 100 & 49.2 & 32.9 & 29.8 & 25.5 & 29.5 & 34.4 & 37.5 & 33.1 \\
\hline 9 & 90.6 & 90.6 & 90.7 & 90.7 & 88.6 & 86.1 & 88.1 & 92.9 & 100 & 33.0 & 29.4 & 27.4 & 28.9 & 35.3 & 36.5 & 33.2 \\
\hline 10 & 86.9 & 86.9 & 86.6 & 86.9 & 90.7 & 86.1 & 93.8 & 87.9 & 87.9 & 100 & 29.6 & 25.9 & 28.7 & 42.8 & 33.0 & 53.0 \\
\hline 11 & 85.7 & 85.6 & 85.7 & 85.6 & 87.0 & 85.8 & 86.9 & 86.5 & 86.4 & 86.8 & 100 & 27.5 & 60.8 & 30.4 & 30.0 & 29.8 \\
\hline 12 & 84.6 & 84.5 & 84.6 & 84.6 & 85.2 & 88.0 & 85.4 & 85.4 & 85.3 & 85.2 & 85.5 & 100 & 27.9 & 25.8 & 26.6 & 25.7 \\
\hline
\end{tabular}




\begin{tabular}{|l|l|l|l|l|l|l|l|l|l|l|l|l|l|l|l|l|}
\hline $\mathbf{1 3}$ & 85.5 & 85.4 & 85.4 & 85.4 & 86.2 & 85.8 & 86.3 & 86.5 & 86.2 & 86.2 & 95.3 & 85.6 & 100 & 29.4 & 29.5 & 28.8 \\
\hline $\mathbf{1 4}$ & 87.6 & 87.7 & 87.6 & 87.7 & 94.0 & 86.6 & 91.6 & 88.5 & 89.2 & 91.2 & 87.3 & 85.7 & 86.8 & 100 & 34.3 & 43.6 \\
\hline $\mathbf{1 5}$ & 88.1 & 88.0 & 88.1 & 88.0 & 88.7 & 86.4 & 88.2 & 90.0 & 89.2 & 88.1 & 86.8 & 85.8 & 86.5 & 89.3 & 100 & 33.4 \\
\hline $\mathbf{1 6}$ & 87.1 & 87.0 & 86.9 & 87.0 & 91.0 & 86.2 & 92.5 & 88.1 & 88.0 & 93.6 & 86.8 & 85.5 & 86.3 & 91.5 & 88.2 & 100 \\
\hline
\end{tabular}

564

(1) Rahnella perminowiae SL6 ${ }^{\top}$ (GCA_019049755.1), (2) Rahnella perminowiae C60 (GCA_019049695.1), (3) Rahnella perminowiae L72c (GCA_019049715.1), (4) Rahnella perminowiae L151-1A (GCA_019049735.1), (5) Rahnella bonaserana H11b (GCA_019049675.1), (6) Rahnella rivi FC061912-K ${ }^{\top}$ (GCA_019049655.1), (7) Rahnella ecdela FRB 231 ${ }^{\top}$ (GCA_019049625.1), (8) Rahnella aquatilis CIP 78.65 (GCA_000241955), (9) Rahnella aceris SAP-19 ${ }^{\top}$ (GCA_011684115), (10) Rahnella bruchi DSM 27398 ${ }^{\top}$ (GCA_003614975), (11) Rahnella contaminans Lac-M11 ${ }^{\top}$ (GCA_011065485), (12) Rahnella inusitata DSM 30078 ${ }^{\top}$ (GCA_003602055), (13) Rahnella laticis SAP-17 ${ }^{\top}$ (GCF_015644585), (14) Rahnella variigena CIP 105588 ${ }^{\top}$ (GCA_003602185), (15) Rahnella victoriana DSM 27397 ${ }^{\top}$ (GCA_004330295), (16) Rahnella woolbedingensis DSM 27399 ${ }^{\top}$ (GCA_003602095).

$\top^{\top}=$ type strain. 
Table 2: Phenotypic characteristics allowing differentiation of Rahnella perminowiae sp. nov., Rahnella bonaserana sp. nov., Rahnella rivi sp. nov. and

\begin{tabular}{|c|c|c|c|c|c|c|c|c|c|c|c|c|c|}
\hline & 1 & 2 & 3 & 4 & 5 & 6 & 7 & 8 & 9 & 10 & 11 & 12 & 13 \\
\hline Arginine dihydrolase & + & + & + & - & - & $+^{a}$ & - & - & - & - & - & - & - \\
\hline Acetoin production & - & - & + & - & $+{ }^{a}$ & - & - & - & $+{ }^{a}$ & - & + & $+{ }^{a}$ & - \\
\hline Gelatinase production & - & - & - & - & - & - & + & - & $+^{b}$ & - & $+^{b}$ & w+ & w+ \\
\hline \multicolumn{14}{|l|}{ Acid from: } \\
\hline D-sorbitol & + & + & - & - & + & + & $v^{c}$ & + & $v^{c}$ & - & + & + & - \\
\hline $\begin{array}{l}\text { methyl- } \alpha-D- \\
\text { glucopyranoside }\end{array}$ & + & - & + & - & - & v & $\mathrm{v}^{c}$ & - & $\mathrm{v}^{c}$ & - & - & - & - \\
\hline$N$-acetylglucosamine & $(+)$ & - & - & + & + & + & + & + & + & $v^{c}$ & + & + & + \\
\hline D-melezitose & - & - & - & - & - & + & - & - & - & - & - & - & - \\
\hline gentiobiose & $(+)$ & - & + & + & + & $(+)$ & + & + & + & + & + & + & + \\
\hline
\end{tabular}




\begin{tabular}{|c|c|c|c|c|c|c|c|c|c|c|c|c|c|}
\hline D-turanose & - & - & + & - & - & + & - & - & $\mathrm{v}^{c}$ & - & - & - & - \\
\hline D-fucose & + & + & - & + & $+^{a}$ & $(+)^{d}$ & - & - & - & - & $(+)^{d}$ & + & - \\
\hline D-arabitol & - & - & - & + & - & - & + & + & + & - & - & - & - \\
\hline \multicolumn{14}{|l|}{ Utilisation of: } \\
\hline D-turanose & - & - & + & - & - & + & v & ND & + & ND & - & - & - \\
\hline stachyose & - & - & + & - & - & v & + & ND & + & ND & v & - & - \\
\hline$N$-acetyl-D-galactosamine & - & - & $w+$ & + & $w+$ & - & + & ND & - & ND & - & - & + \\
\hline$N$-acetyl neuraminic acid & - & + & + & - & $w+$ & - & + & ND & + & ND & - & + & + \\
\hline 3-methyl glucose & - & + & - & + & + & - & + & ND & - & ND & - & - & + \\
\hline D-serine & - & + & + & + & + & - & + & ND & + & ND & + & + & + \\
\hline D-sorbitol & + & + & - & - & + & + & - & ND & v & ND & + & + & - \\
\hline D-arabitol & - & - & - & + & - & - & + & ND & + & ND & - & - & - \\
\hline D-aspartic acid & - & + & + & + & + & + & + & ND & - & ND & + & v & + \\
\hline D-serine & - & + & + & + & + & - & + & ND & - & ND & + & + & + \\
\hline minocycline & - & + & - & - & - & - & - & ND & - & ND & + & - & - \\
\hline quinic acid & + & + & - & + & + & + & + & ND & - & ND & + & + & + \\
\hline tween 40 & - & - & + & + & + & v & + & ND & + & ND & - & - & + \\
\hline acetoacetic acid & - & - & + & + & + & - & + & ND & - & ND & - & + & + \\
\hline sodium butyrate & - & + & - & + & - & - & - & ND & - & ND & + & - & - \\
\hline
\end{tabular}


591

,$+ 90-100 \%$ strains +; (+), $70-89 \%$ strains +; -, $91-100 \%$ strains -; w+, weakly positive; $v$, variable; ND, not determined

$592 \quad{ }^{a}$ Differs from Jeon et al., 2021

$593 \quad{ }^{b}$ Late reaction for type strain

$594{ }^{c}$ Positive for type strain

$595 \quad{ }^{d}$ Negative for type strain

596

597

598

599

600

601

602

603

604

605

606

607

608

609

610

611 
Table 3: Fatty acid composition (percentage of peak areas) of Rahnella species.

614

615

616

$1=$ Rahnella perminowiae sp. nov. $(n=4), 2=$ Rahnella bonaserana sp. nov. $(n=1), 3=$ Rahnella rivi sp. nov. $(n=1), 4=$ Rahnella ecdela sp. nov. $(n=1), 5=$ Rahnella aquatilis $(n=1), 6=$ Rahnella aceris $(n=4$, type strain not included), $7=$ Rahnella bruchi $(n=3), 8=$ Rahnella contaminans $(n=1)$, $9=$ Rahnella inusitata $(n=3), 10=$ Rahnella laticis $(n=2), 11=$ Rahnella variigena $(n=4), 12=$ Rahnella victoriana $(n=4), 13=$ Rahnella woolbedingensis $(n=3)$. Values are expressed as the average if more than one strain per species were investigated, with the standard deviation shown in parentheses. Data for $5,7,9,11-13$ taken from [5], data for 8, 10 taken from [7] . $n=$ number of strains.

\begin{tabular}{|c|c|c|c|c|c|c|c|c|c|c|c|c|c|}
\hline Fatty acid & 1 & 2 & 3 & 4 & 5 & 6 & 7 & $8^{*}$ & 9 & $10^{*}$ & 11 & 12 & 13 \\
\hline \multicolumn{14}{|c|}{ Saturated fatty acids } \\
\hline $\mathrm{C}_{12: 0}$ & $\begin{array}{c}4.1 \quad( \pm \\
0.1)\end{array}$ & 3.9 & 3.9 & 4.5 & 4.2 & $\begin{array}{c}4.1 \\
( \pm 0.0)\end{array}$ & $\begin{array}{c}3.5 \\
( \pm 0.0)\end{array}$ & 3.2 & $\begin{array}{c}3.6 \\
( \pm 0.2)\end{array}$ & $\begin{array}{c}3.4 \\
( \pm 0.07)\end{array}$ & $\begin{array}{c}3.6 \\
( \pm 0.1)\end{array}$ & $\begin{array}{c}3.6 \\
( \pm 0.3)\end{array}$ & $\begin{array}{c}3.2 \\
( \pm 0.0)\end{array}$ \\
\hline$C_{14: 0}$ & $\begin{array}{c}5.5 \\
( \pm 0.1)\end{array}$ & 5.7 & 5.8 & 6.1 & 6.4 & $\begin{array}{c}5.5 \\
( \pm 0.1)\end{array}$ & $\begin{array}{c}6.0 \\
( \pm 0.3)\end{array}$ & 7.0 & $\begin{array}{c}6.2 \\
( \pm 0.2)\end{array}$ & $\begin{array}{c}6.6 \\
( \pm 0.8)\end{array}$ & $\begin{array}{c}6.6 \\
( \pm 0.3)\end{array}$ & $\begin{array}{c}6.6 \\
( \pm 0.3)\end{array}$ & $\begin{array}{c}6.4 \\
( \pm 0.1)\end{array}$ \\
\hline$C_{16: 0}$ & $\begin{array}{c}33.2 \\
( \pm 0.4)\end{array}$ & 34.6 & 33.0 & 38.5 & 33.1 & $\begin{array}{c}33.6 \\
( \pm 0.3)\end{array}$ & $\begin{array}{c}34.1 \\
( \pm 0.5)\end{array}$ & 31.1 & $\begin{array}{c}34.4 \\
( \pm 1.4)\end{array}$ & $\begin{array}{c}30.9 \\
( \pm 5.9)\end{array}$ & $\begin{array}{c}34.4 \\
( \pm 2.1)\end{array}$ & $\begin{array}{c}34.8 \\
( \pm 0.3)\end{array}$ & $\begin{array}{r}34.2 \\
( \pm 1.1)\end{array}$ \\
\hline \multicolumn{14}{|c|}{$\begin{array}{l}\text { Unsaturated fatty } \\
\text { acids }\end{array}$} \\
\hline$C_{18: 1} \omega 7 c$ & $\begin{array}{c}9.3 \\
( \pm 0.9)\end{array}$ & 4.6 & 12.1 & 7.3 & 8.4 & $\begin{array}{c}9.0 \\
( \pm 0.2)\end{array}$ & $\begin{array}{c}2.6 \\
( \pm 0.9)\end{array}$ & 8.1 & $\begin{array}{c}9.6 \\
( \pm 0.8)\end{array}$ & $\begin{array}{c}10.1 \\
( \pm 3.4)\end{array}$ & $\begin{array}{c}5.4 \\
( \pm 1.1)\end{array}$ & $\begin{array}{c}6.9 \\
( \pm 0.5)\end{array}$ & $\begin{array}{c}8.2 \\
( \pm 1.3)\end{array}$ \\
\hline $\begin{array}{l}\text { Cyclopropa } \\
\text { acids }\end{array}$ & & & & & & & & & & & & & \\
\hline$C_{17: 0}$ & $\begin{array}{c}27.7 \\
( \pm 1.3)\end{array}$ & 29.7 & 19.8 & 28.7 & 28.7 & $\begin{array}{c}23.7 \\
( \pm 0.5)\end{array}$ & $\begin{array}{c}30.7 \\
( \pm 0.7)\end{array}$ & 28.0 & $\begin{array}{c}24.2 \\
( \pm 2.4)\end{array}$ & $\begin{array}{c}24.2 \\
( \pm 3.1)\end{array}$ & $\begin{array}{c}30.3 \\
( \pm 0.5)\end{array}$ & $\begin{array}{c}28.1 \\
( \pm 0.6)\end{array}$ & $\begin{array}{r}28.4 \\
( \pm 1.2)\end{array}$ \\
\hline $\mathrm{C}_{19: 0} \omega 8 \mathrm{c}$ & $\begin{array}{c}2.6 \\
( \pm 0.2)\end{array}$ & 4.7 & 0.3 & 5.7 & 2.3 & $\begin{array}{c}1.6 \\
( \pm 0.1)\end{array}$ & $\begin{array}{c}7.9 \\
( \pm 0.7)\end{array}$ & 2.4 & $\begin{array}{c}1.0 \\
( \pm 0.4)\end{array}$ & $\begin{array}{c}1.6 \\
( \pm 0.1)\end{array}$ & $\begin{array}{c}5.0 \\
( \pm 0.5)\end{array}$ & $\begin{array}{c}3.6 \\
( \pm 0.6)\end{array}$ & $\begin{array}{c}3.9 \\
( \pm 0.5)\end{array}$ \\
\hline
\end{tabular}




\begin{tabular}{|c|c|c|c|c|c|c|c|c|c|c|c|c|c|}
\hline $\begin{array}{l}\text { 2: } \mathrm{C}_{14: 0} 3-\mathrm{OH} \text { and/or } \\
\text { iso- } \mathrm{C}_{16: 1}\end{array}$ & $\begin{array}{c}9.5 \\
( \pm 0.2)\end{array}$ & 8.9 & 9.5 & 9.5 & 6.9 & $\begin{array}{c}9.3 \\
( \pm 0.1)\end{array}$ & $\begin{array}{c}9.0 \\
( \pm 0.1)\end{array}$ & 9.0 & $\begin{array}{c}9.1 \\
( \pm 0.4)\end{array}$ & $\begin{array}{c}8.5 \\
( \pm 1.9)\end{array}$ & $\begin{array}{c}8.9 \\
( \pm 0.2)\end{array}$ & $\begin{array}{c}8.8 \\
( \pm 0.3)\end{array}$ & $\begin{array}{c}8.7 \\
( \pm 0.1)\end{array}$ \\
\hline $\begin{array}{l}\text { 3: } C_{16: 1} \omega 7 c \text { and/or } \\
C_{16: 1} \omega 6 c\end{array}$ & $\begin{array}{c}8.4 \\
( \pm 1.3)\end{array}$ & 4.2 & 12.6 & 4.4 & 8.1 & $\begin{array}{c}9.9 \\
( \pm 0.8)\end{array}$ & $\begin{array}{c}1.8 \\
( \pm 0.2)\end{array}$ & 7.2 & $\begin{array}{c}10.1 \\
( \pm 1.8)\end{array}$ & $\begin{array}{c}10.2 \\
( \pm 5.2)\end{array}$ & $\begin{array}{c}2.9 \\
( \pm 0.7)\end{array}$ & $\begin{array}{c}5.0 \\
( \pm 0.6)\end{array}$ & $\begin{array}{c}4.2 \\
( \pm 1.4)\end{array}$ \\
\hline
\end{tabular}

621

${ }^{*}$ Fatty acid analysis for these two species was performed by Jeon et al. [7] following growth on nutrient agar, whereas the remaining Rahnella species were cultured on TSA prior to analysis by Fera Science Ltd. (York, UK). 
640 Figure 1: Maximum likelihood tree based on concatenated partial $g y r B, r p o B$, atpD and infB gene 641 sequences of proposed novel Rahnella species, existing Rahnella species and the closest phylogenetic 642 neighbours. Bootstrap values after 1000 replicates are expressed as percentages (values $>50 \%$ 643 shown). Hafni aalvei (ATCC $13337^{\top}$ ) is included as an outgroup. The scale bar indicates the fraction of 644 substitutions per site. ${ }^{\top}=$ type strain $^{2}$

645

646 Figure 2: Phylogenomic tree of proposed novel Rahnella species, existing Rahnella species and the 647 closest phylogenetic neighbours. GBDP pseudo-bootstrap support values $>60 \%$ shown at the nodes 648 (from 100 replicates), with an average branch support of $85.4 \%$. The branch lengths are scaled in 649 terms of GBDP distance formula $d_{5}$. The tree is rooted at the midpoint. GenBank assembly and 650 accession numbers are given in parentheses. ${ }^{\top}=$ type strain 651

652 Figure 3: Transmission electron microscopy of proposed novel Rahnella species displaying their 653 flagella arrangement: (a) Rahnella perminowiae $\mathrm{SL}^{\top}$, (b) Rahnella bonaserana $\mathrm{H}_{11} \mathrm{~b}^{\top}$, (c) Rahnella rivi 654 FC061912-K' ${ }^{\top}$, (d) Rahnella ecdela FRB $231^{\top}$. Scale bar, $1 \mu \mathrm{m}$. 